\title{
NEW CRITERIA FOR MULTIVALENTLY MEROMORPHIC CONVEX FUNCTIONS OF ORDER $\alpha$
}

\section{SERAP BULUT}

Abstract. Let $\mathscr{J}_{n+p-1}(\alpha)(p \in \mathbb{N}, n>-p, 0 \leqslant \alpha<p)$ denote the class of functions of the form

$$
f(z)=\frac{1}{z^{p}}+\frac{a_{0}}{z^{p-1}}+\frac{a_{1}}{z^{p-2}}+\cdots
$$

which are regular and $p$-valent in the punctured unit disc

$$
\mathbb{U}^{*}=\{z \in \mathbb{C}: 0<|z|<1\}
$$

and satisfy the condition

$$
\operatorname{Re}\left\{\frac{\left(D^{n+p} f(z)\right)^{\prime}}{\left(D^{n+p-1} f(z)\right)^{\prime}}-(p+1)\right\}<-\frac{p(n+p-1)+\alpha}{n+p},
$$

where

$$
D^{n+p-1} f(z)=\frac{1}{z^{p}(1-z)^{n+p}} * f(z) .
$$

It is proved that $\mathscr{J}_{n+p}(\alpha) \subset \mathscr{J}_{n+p-1}(\alpha)$. Since $\mathscr{J}_{0}(\alpha)$ is the class of $p$-valently meromorphic convex functions of order $\alpha(0 \leqslant \alpha<p)$, all functions in $\mathscr{J}_{n+p-1}(\alpha)$ are $p$-valently meromorphic convex of order $\alpha$. Further, we consider the integral operators of functions in $\mathscr{J}_{n+p-1}(\alpha)$.

Mathematics subject classification (2010): 30C45. product.

Keywords and phrases: Meromorphic function, Multivalent function, Convex function, Hadamard

\section{REFERENCES}

[1] M. K. Aouf AND H. M. SRIVASTAVA, A new criterion for meromorphically p-valent convex functions of order alpha, Math. Sci. Res. Hot-Line 1, 8 (1997), 7-12.

[2] S. K. BAJPAI, A note on a class of meromorphic univalent functions, Rev. Roumaine Math. Pures Appl. 22, 3 (1977), 295-297.

[3] H. E. Darwish, M. K. Aouf AND G. S. SăLăGEAN, A new criterion for meromorphically convex functions of order $\alpha$, Gen. Math. 13, 3 (2005), 71-80.

[4] R. M. Goel And N. S. Sohi, On a class of meromorphic functions, Glas. Mat. Ser. III 17 (37), 1 (1982), 19-28.

[5] I. S. JACK, Functions starlike and convex of order $\alpha$, J. London Math. Soc. (2) 3 (1971), 469-474.

[6] S. S. Miller AND P. T. Mocanu, Differential subordinations. Theory and applications, vol. 225. of Monographs and Textbooks in Pure and Applied Mathematics, Marcel Dekker, New York, NY, USA, 2000.

[7] B. A. URalegaddi AND M. D. GANigi, A new criterion for meromorphic convex functions, Tamkang J. Math. 19, 1 (1988), 43-48.

[8] B. A. URAlegaddi And H. S. Patil, A new criterion for p-valent meromorphic convex functions, Math. Chronicle 18 (1989), 75-77. 